\title{
Formaç̃ão Inventiva de Professores e Políticas de Cognição
}

\author{
Inventive formation of teachers and cognition policies
}

Resumo: Este texto discute a formação de professores articulando-a ao problema do conhecer. O trabalho evidencia o conhecer no seio das ciências cognitivas, da maneira proposta por Francisco Varela. Em seguida, analisa a relação paradoxal entre aprender e desaprender o prescrito na formação de professores, pensando-a como um campo de relação de forças. Tal noção força a pensar uma formação inventiva. Esta conjuga políticas de cognição com produção de subjetividade. O trabalho apresenta, finalmente, um relato de experiência de sala de aula, deslocando conceitos que expressam uma política de cognição. A articulação entre conhecer e formação de professores, fala dos deslocamentos e das políticas que possibilitam experiências de tensionamento dos modelos rígidos e predeterminados de conhecer para não confundir uma forma de ensinar com o único modo de praticá-lo. Assim, o que há é a expressão de uma política geradora de experiências, pequenas invenções e não uma prescrição replicável.

Palavras-chave: Formação inventiva de professores. Políticas de cognição. Enação. Invenção.

Abstract: This text discusses teacher's formation articulating it with the matter of knowing. The paper shows knowing within the cognitive sciences, in the way proposed by Francisco Varela. Then analyzes the paradoxical relation between learn and unlearn the prescribed in teacher's formation, thinking it as a field of forces relationships. This notion forces you to think a inventive formation. This one conjugates cognitive policies with production of subjectivity. The paper presents, finally, a report of classroom experiences, shifting concepts that express a policy of cognition. Articulation between knowing and teacher's formation refers to shifts and policies that allow tensioning experiences of rigid and predetermined models of knowing in order to not confuse a way to teach with the only manner of doing it. Therefore, what exist is the expression of a policy that create experiences, little inventions and not a replicable prescription.

Keywords: Inventive formation of teachers. Cognition policies. Enaction. Invention.
DIAS, Rosimeri de Oliveira. Formação Inventiva de Professores e Políticas de Cognição. Informática na Educação: teoria \& prática, Porto Alegre, v. 12, n. 2, p. 164-174, jul./dez. 2009.

\section{Rosimeri de Oliveira Dias \\ Universidade do Estado do Rio de Janeiro}

\section{I ntrodução}

E ste trabalho discute formação de professores articulando-a ao problema do conhecer (DIAS, 2008). Desse modo, o problema da formação de professores não reside somente nos produtos a serem alcançados. Tal problemática tampouco fixa metas na busca de leis gerais dos processos cognitivos, reduzindo a cognição a formas de representação simbólica e solução de problemas. Neste trabalho, o problema da formação de professores convoca outra noção e habita o conhecer pela problematização que tensiona a própria formação.

Então, para colocar o problema da formação no âmbito do conhecer é necessário avançar nos limites postos por teorias que o situam no interior de suas condições universais. Por isso, de início, analiso o conhecer no seio das ciências cognitivas, da maneira proposta por Francisco Varela. Em seguida, dando mais um passo na articulação entre o problema da formação de professores e os estudos da cognição, analiso a relação paradoxal entre aprender e desaprender o prescrito na formação de professores. Tal noção força a pensar uma formação inventiva (DIAS, 2008) que se expressa por deslocamentos e por políticas de cognição que tensionam a dependência de modelos rígidos e predeterminados, evidenciando a necessidade de não con- 
fundir uma forma de ensinar com o único modo de praticá-lo. Para concluir, o trabalho apresenta um relato de uma experiência de sala de aula, não como um modelo a ser seguido, mas como uma possibilidade de deslocamento de conceitos que expressam uma política de cognição atenta a produção de subjetividade e a um conhecer enativo (VARELA, 1994) no campo da formação de professores.

O que o conceito de políticas de cognição evidencia é que o problema do conhecer não se esgota na sua definição teórica ou no debate de modelos utilizados para seu entendimento. Uma política de cognição expressa uma distinção ética e política e, ao mesmo tempo, envolve uma posição em relação ao mundo e a si mesmo, uma atitude, um ethos (KASTRUP; TEDESCO; PASSOS, 2008). Neste sentido, formar não é apenas dar forma a, mas envolve também estratégias de estranhamento de políticas de cognição cristalizadas para dar lugar a outros modos de relação com mundo, com pessoas, consigo mesmo, com aprender e com conhecer.

\section{Ciências Cognitivas e Formação de Professores}

Varela (1994) chama a atenção para o fato de que com as ciências cognitivas o fenômeno da mente humana e do conhecer é analisado na interface entre ciência, tecnologia e público. O autor problematiza a noção comum de que o conhecer está ligado ao processamento da informação, e completa dizendo que "[...] o ponto forte da cognição é precisamente a sua capacidade para exprimir o significado e as regularidades; a informação deve aparecer não como uma ordem intrínseca, mas como uma ordem que emerge das próprias atividades cognitivas [...]" (VARELA, 1994, p. 11).

Para esse autor, as ciências cognitivas são um híbrido multidisciplinar - inteligência artificial, neurociências, lingüística, psicologia cognitiva e epistemologia - em que opera uma rede de investigações, informações e comunicações preocupada com a análise da mente humana e do conhecimento. Essa análise coloca em evidência as decisões políticas relativas às orientações que as suas correntes seguem. Um exame limitado às simples incidências econômicas e que não considere as diferentes escolhas agravaria a inércia das estruturas cognitivas. Nesse sentido, Varela orienta seus estudos de modo atento aos atravessamentos sócio-político-epistemológicos que as ciências cognitivas vêm sofrendo nos seus 60 anos de existência.

Nesse itinerário, Varela aponta quatro etapas percorridas pelas ciências cognitivas: cibernética, cognitivismo, conexionismo (ou emergência) e enação. A primeira etapa marcou os primeiros anos das ciências cognitivas, entre 1940-1956, em que se afirmava a possibilidade de se estudar o cérebro recorrendo-se a mecanismos explícitos e a formalismos matemáticos. Varela acentua importantes resultados dessa etapa. Primeiro, a escolha pela lógica matemática para decifrar o funcionamento do sistema nervoso e do raciocínio humano. Em seguida, o começo da teoria dos sistemas, que procura exprimir os princípios gerais que regem qualquer sistema complexo. Outro resultado da cibernética refere-se ao aparecimento da teoria da informação como uma abordagem estatística do sinal e dos canais de comunicação. O último resultado alude ao aparecimento dos primeiros robôs autômatos, que incorporam uma auto-organização parcial. Esses resultados são identificados como marcos importantes para as outras três etapas, que configuram as três abordagens das ciências cognitivas: cognitivismo, conexionismo e enação.

A hipótese cognitivista surge, segundo Varela (1994), no ano de 1956, em duas conferências, realizadas em Cambridge e Dartmouth. A principal ideia emergente dessas conferências é pautada no fato de que "[...] a inteligência se aproxima de tal forma daquilo que é um computador, e que a cognição pode ser definida pela computação de representações simbólicas [...]" (VARELA, 1994, p. 29). Ou seja, para o cognitivismo, a única forma de explicar a inteligência está localizada na hipótese de que a cognição consiste em representações sob a forma de código simbólico num cérebro ou numa máquina.

Nesse sentido, Varela (1994) chama a atenção para dois tipos de representação. Uma, em sentido fraco, geralmente admitida pelo autor, define a representação por interpretação. Em seu sentido semântico, refere-se a “[...] tudo o que talvez possa ser compreendido a respeito de qualquer coisa" (VARELA, 1994, p. 79). Essa representação é fraca, porque não possui fundamento epistemológico e ontológico, mas ela afirma o seu sentido pragmático. O outro 
tipo de representação, em sentido forte, possui implicações epistemológicas e ontológicas, surgindo quando, “[...] por generalização da acepção fraca, é formulada uma teoria completa dos mecanismos perceptivos, lingüísticos ou cognitivos em geral [...]" (VARELA, 1994, p. 79). A representação em sentido forte presume que o mundo é pré-definido e suas propriedades são estabelecidas antes de qualquer atividade cognitiva. Desse modo, essa representação surge por generalizações, formulando uma teoria completa dos mecanismos cognitivos, onde o mundo é dado a priori, a cognição diz respeito a esse mundo e o conhecer desse mundo dado representa um mapa que oferece condições de aprender a agir nele.

Os efeitos da lógica ortodoxa cognitivista (como, por exemplo, a escala de performance e o know-how dos peritos) mostram que o tratamento da informação não é tão eficiente como se anunciou. Nas palavras de Varela:

\footnotetext{
As duas décadas da dominação cognitivista saldaram-se pela seguinte convicção, que foi crescendo entre os investigadores: na escala da performance é agora necessário inverter o perito e a criança. [...] Tornava-se óbvio que a inteligência mais profunda e mais fundamental era a do bebê que adquire a linguagem a partir de um fluxo cotidiano de palavras dispersas, ou reconstitui ainda objetos significantes a partir de um fluxo difuso de luz. As arquiteturas cognitivas tinham-se distanciado demasiado das raízes biológicas, não porque se deva reduzir o cognitivo ao biológico, mas porque a tarefa mais banal cumprida pelo mais pequeno dos insetos será sempre efetuada mais rapidamente do que por intermédio da estratégia computacional proposta pela ortodoxia cognitivista. (VARELA, 1994, p. 45)
}

Com efeito, a abordagem conexionista surge como alternativa cujo ponto de partida não é a descrição simbólica abstrata, mas todo um conjunto, ou uma rede de aspectos constituintes ligados entre si, que exprimem propriedades globais da cognição (neurônios, aprendizagem). A estratégia conexionista não se baseia mais em símbolos e regras, mas se localiza na construção de um sistema cognitivo a partir de constituintes simples que, dinamicamente, podem estar ligados entre si de forma muito densa.

A cognição é estudada no seio de vastos conjuntos que aparecem e desaparecem constantemente durante suas interações cooperativas, em que as reações, múltiplas e diversas, estão consoantes com o contexto. A cognição é, portanto, um sistema altamente cooperativo representado por uma rede de interconexões (locais e globais) entre seus elementos constituintes, uns implicados com os outros. O que acontece na rede será uma função cognitiva de seus constituintes interconectados.

Varela, Thompson e Rosch (2003) asseveram, no entanto, que a estratégia conexionista baseia-se, novamente, em metáforas e ideias. Os modelos conexionistas não possuem mais as descrições simbólicas abstratas como referência, mas um conjunto de componentes "[ . . . ] não-inteligentes, simples, semelhantes aos componentes neurais que, quando adequadamente conectados, exibem interessantes propriedades globais que incorporam e expressam as capacidades cognitivas [ . . . ]" (VARELA; THOMPSON; ROSCH, 2003, p. 101). Desse modo, no conexionismo há necessidade de se introduzir no sistema cognitivo as conexões adequadas, definidas pelo tipo de tarefa, de forma geralmente arbitrária.

A quarta e última abordagem das ciências cognitivas descrita por Varela é chamada enação. Em Varela, Thompson e Rosch (2003), a palavra enação foi traduzida por atuação, mas neste trabalho utilizo o neologismo enação (do verbo inglês enact) porque considero que ele traduz melhor a noção de Varela de fazeremergir, que luta contra a ideia de representação simbólica das perspectivas anteriores. Nas palavras do autor:

A faculdade mais importante de qualquer cognição viva é precisamente, em larga medida, colocar as questões pertinentes que surgem a cada momento da vida. Estas não são predefinidas mas en-agidas, nós fazêmo-las emergir sobre um pano de fundo, sendo os critérios de pertinências ditados pelo nosso senso comum, sempre de maneira contextual. [...] não será inútil insistir no fato de isto constituir uma crítica à utilização da noção de representação no seio das ciências cognitivas, visto que só um mundo predefinido pode ser representado. (VARELA, 1994, p. 72-73)

Nessa abordagem, há uma preocupação mais com a ação do que com a representação. A cognição é pensada como um fazer-emergir criador de si e do mundo, com a condição de assegurar a perenidade do sistema cognitivo. O que se tem não é a solução de problemas por representações, mas sim a invenção de problemas. 
A representação já não tem um papel-chave, a inteligência já não se define como sendo a faculdade de resolver um problema, mas como a de penetrar num mundo partilhado. Enfim, da mesma maneira que o conexionismo vem do cognitivismo e de uma maior proximidade com o cérebro, também a abordagem da enação dá mais um passo na mesma direção para englobar, de igual modo, a temporalidade da vida, quer se trate de uma espécie (evolução), de um indivíduo (ontogênese) ou de uma estrutura social (cultura). (VARELA, 1994, p. 89)

Com o intuito de combater a lógica da representação simbólica e da solução de problemas, Varela (1994) distingue a enação das demais abordagens, a partir de tensões que orientam a processualidade do conhecer. Essas tensões possibilitam diferenciar o modo como o conhecer é analisado na enação, de como ele é pensado pelas outras perspectivas das ciências cognitivas. As distinções são demonstradas quando a cognição está dedicada a uma tarefa e quando ela é criação; quando ela é solução de problemas e quando é problematização; quando a cognição resume processos abstratos e simbólicos e quando ela é um historial encarnado; quando possui um mundo predefinido e quando possui um mundo enagido; quando é representação e quando ela é uma ação produtiva.

Kastrup (1999) realiza um trabalho em rede agenciando a filosofia de Bergson, Deleuze e Guattari, e a biologia de Maturana e Varela, para pensar um conceito de cognição ampliada. Tal cognição “[ . . . ] não se restringe à inteligência e à solução de problemas [ . . . ]" (Ibidem, p. 197), mas insere o tempo, o coletivo e a invenção de si e do mundo no debate que busca uma deriva do conhecer como recognição ou representação. Uma cognição ampliada, então, forja uma atividade cognitiva incorporada numa rede rizomática, divergindo do que uma psicologia cognitiva concebe. Desse modo, tal conceito tensiona a investigação psicológica que restringe o conhecer à solução de problemas e estruturas cognitivas necessárias, para analisar o conhecer por sua potência inventiva. Ao analisar o conceito de enação de Varela, Kastrup (1999) conclui que este autor redireciona uma abordagem abstrata do conhecer para uma abordagem concreta. Esta perspectiva reside na convicção de que uma cognição é corporificada, encarnada e distinta da cognição entendida como processamento mental.
Desse modo, a noção de enação polemiza a de representação presente nas demais abordagens. O que é possível destacar, com este breve histórico das ciências cognitivas, é que o conhecer pode percorrer caminhos outros, diferentes daqueles postulados pela representação simbólica e pela solução de problemas, que pensam a cognição como sistema de entrada e saída. Caminhos que evidenciam a dimensão temporal e incorporada da cognição.

Como um conceito potente, enação expressa o conhecer em sua dimensão experiencial, onde suas unidades são concretas, incorporadas e vividas. Tal conceito permite deslocar e derivar de uma formação como dar forma a, que é sempre um saber-fazer performatizado ${ }^{1}$ em padrões, manuais e regras gerais que seguem princípios invariantes, para uma formação inventiva. Com esse deslocamento, por meio de um conhecer incorporado e concreto, é possível agenciar práticas que fazem emergir uma plasticidade, no campo da formação, que caminha para um processo de produção de sentido.

Assim, uma cognição que trata o aprender pela problematização e que lida com a diferença força o movimento que desloca a formação voltada somente para seus resultados e fins, para colocá-la no coração das experiências de aprendizagem que emergem do seu percurso, regidas por invenção de problemas. Esses deslocamentos são permanentes, acentuando sempre que há caminhos de fuga das lógicas deterministas e limitadoras do pensamento no campo da formação de professores. Por isso, aqui, formação de professores é pensada por aquilo que move os encontros, no meio dos quais há tensão e possibilidade entre os diferentes modos e formas de pensar e de fazer o conhecer. O desafio é tomar o conhecer como invenção de problemas, abrindo-se para as imprevisibilidades e pequenas invenções que emergem dos contextos de formação.

\footnotetext{
1 Este conceito será um, entre outros, que aparecerão no trabalho para expressar ideias forjadas no contexto das análises. Performatizado, evidencia o desempenho de um educador cuja qualificação é a priori pensada por meio de manuais e de leis gerais que generalizam e essencializam a tarefa docente nas relações de saber-fazer.
} 


\section{O Cultivo dos Paradoxos Entre Aprendizagem e Desaprendizagem do Prescrito na Formação I nventiva de Professores}

É no meio polêmico dos estudos da cognição que se expressa uma formação inventiva. Formação essa emergente da ligação problematizada entre as redes de conhecimento e as políticas de cognição existentes na própria formação. Quando falo em políticas de cognição me refiro aos diferentes modos de se relacionar com o conhecer, que se vinculam as práticas efetivas e aos usos e efeitos de tais práticas na formação e na vida. Políticas de cognição é um conceito que evidencia que o conhecer referese à uma atitude, um ethos.

Sendo assim, o cognitivismo não é apenas um problema teórico, mas um problema político. Ele é uma das configurações que nossa cognição assume. Ele não dorme em páginas dos livros, mas nos habita, e muitas vezes de maneira silenciosa. Os pressupostos do modelo da representação - a preexistência de um sujeito cognoscente e de um mundo dado que se dá a conhecer - são muitas vezes tão enraizadas em nós que se confundem com uma atitude natural. [ . . . ] Por outro lado, aproximar conhecimento e criação, afirmar que a ação de conhecer configura de modo recíproco e indissociável o sujeito e o objeto, o si e o mundo, não é apenas propor um novo entendimento da cognição. É um convite a adotar uma certa maneira de estar no mundo, de habitar um território existencial e de se colocar na relação de conhecimento. A recusa da crença num mundo dado que apenas representamos, que coloca os problemas que devemos solucionar e ao qual devemos nos adaptar, não é de modo algum algo trivial. A ideia de que o mundo não é dado, mas efeito de nossa prática cognitiva, expressa uma política criacionista. [ . . . ] Assumir essa postura requer uma virada, uma reversão da atitude naturalizada, o que exige, em princípio, um esforço. Mas pode se transformar, com a prática, numa atitude encarnada, configurando uma nova política cognitiva. (KASTRUP, TEDESCO, PASSOS, 2008, p. 8)

De início, afirmo que há um modo tradicional e pedagogizante ${ }^{2}$ de colocar a questão da formação de professores, dizendo que no momento em que o aluno e o professor se subme-

2 Um modo naturalizado que expressa uma formação universal e que se dá por aplicação de um saber prévio generalizante. tem ao conhecimento desde sempre aín ${ }^{3}$, eles se ligam ao conhecer que já está posto, ou a relação com o saber. Tal relação prende-os ao seu percurso de informação individualizante, que transmite e ensina um saber com o objetivo da manutenção e perpetuação do mesmo. Essa é a maneira cognitivista de colocar a questão da formação de professores.

É possível colocar o problema da formação de outra maneira: não mais supondo inicialmente o direito ao acesso ao conhecimento, não mais estabelecendo de início essa ligação voluntária e contratual com a transmissão e com os especialismos pedagogizantes, mas colocando-a do seguinte modo: O que um questionamento sistemático, ensaiado, teórico-prático do conhecer (como enação) tem a dizer sobre a formação de professores e sua ligação com a transmissão técnica-metodológica à qual ela se encontra presa? Não se trata mais de falar o que eu posso dizer da formação, mas, considerando a decisão e o esforço de desfazer o vínculo que me liga aos modos de formar como representação, o que é feito do conhecer e dos modos de ensino recognitivos? Ou seja, não é mais a crítica da representação da informação em termos de aprende ou não aprende, em termos de ciência ou de prática, não é mais a crítica da representação em sentido forte (VARELA, 1994) que deverá servir de indicador para definir a legitimidade do ensino ou para denunciar sua ilegitimidade. É o deslocamento do formar como solução de problemas que anima a invenção de problemas no campo da formação de professores. Tal análise evidencia-se na experiência, como um ethos, num campo de relação de forças. Ela é expressa "[ . . . ] muito mais sobre uma atitude que sobre uma tese" (FOUCAULT, 2007, p. 293).

Desse modo, o cultivo do paradoxo entre aprendizagem e desaprendizagem no campo da formação de professores consiste em manter vivo um campo problemático que tensiona as certezas, os apriorismos especialistas, e propõe uma atitude transversal de deslocamentos que necessita experienciar e ensaiar diariamente políticas de cognição. Isso implica alimentar encontros de formação que deem ênfase ao agenciamento, que, para Deleuze e Parnet:

3 Como uma imagem dogmática do pensamento (DELEUZE, 1988), o pressuposto não é posto em discussão e opera como princípio do pensamento. 
É uma multiplicidade que comporta termos heterogêneos, e que estabelece ligações, relações entre eles, através das idades, dos sexos, dos reinos - através de naturezas diferentes. A única unidade do agenciamento é de co-funcionamento: é uma simbiose, uma simpatia. O que é importante, não são nunca as filiações, mas as alianças ou as misturas; não são as hereditariedades, as descendências, mas os contágios, as epidemias, o vento. [ . . . ] Um agenciamento nunca é tecnológico, passa-se até o contrário. Os utensílios pressupõem sempre uma máquina, e a máquina é sempre social antes de ser técnica. Há sempre uma máquina social que seleciona ou atribui os elementos técnicos empregues. Um utensílio permanece marginal ou pouco utilizado enquanto não existe a máquina social ou o agenciamento coletivo [ . . . ]. (DELEUZE; PARNET, 2004, p. 88-89, grifo nosso)

Se um agenciamento possui como unidade um co-funcionamento de uma máquina que é social, então, para cultivar paradoxalmente aprender e desaprender no agenciamento coletivo da formação de professores é necessário animar uma experiência ensaiada em devir na linha do encontro. Esse cultivar expressa um formar com, experienciar com, inventar com, aprender com, dasaprender com. Nesse contexto, é fundamental estar no meio para resistir às armadilhas das máquinas binárias, aquelas que se estendem no espelho das identificações e as que exprimem uma recognição. Como, por exemplo, ser competente $x$ não ser competente, aprender $x$ não aprender... Ao contrário dessa lógica, só se pode agenciar entre os co-funcionamentos extraindo da própria formação toda a desaprendizagem que ela contém, sem formar para, mas co-formação forjando uma formação inventiva. "É preciso que cada um faça o seu caminho. Mas é difícil consegui-lo" (DELEUZE; PARNET, 2004, p. 72). Por isso a importância do co-funcionamento, pois professor e aluno, ao experienciarem uma formação inventiva, pensam em como manter vivo o campo problemático. É fundamental relembrar que professor e aluno não estão juntos, mas entre.

Com um co-funcionamento dos agenciamentos tem-se o cultivo dos paradoxos para externalizar as relações de aprender e desaprender, pois estas só existem porque são exteriores e estão no meio, fazendo do agenciamento uma experimentação que violenta o pensamento e o força a pensar. Por isso, um educador que assume esse cultivo é um experimentador, não um intérprete. Porque pensar é experimentar, problematizar um agenciamento de ideias, de relações e de gestos. Um cultivo em que mestre, aluno, aprender e desaprender tomam o lugar dos conceitos. I nventa!

Agenciando-se com os poetas, "[ .... ] quem não tem ferramentas de brincar, inventa!" (BARROS, 1993). Para pensar com formação E com política $\mathrm{E}$ com cultivo do paradoxo é necessário fazer da experiência de formação inventiva uma ferramenta de pensar. "Não é de pensar um pensamento dialético, como quando se diz [ . . . ] um dá dois que vai dar três" (DELEUZE; PARNET, 2004, p. 75). Trata-se do múltiplo, uma multiplicidade que não está na totalidade. Uma multiplicidade que se agencia na arte do $E$, num gaguejar próprio da formação, num uso minoritário do formar, feito aqui por uma formação inventiva. Em tal formação não se trata de ter um objeto e traçar os passos de um método de ensino para segui-los linearmente. Ao contrário, trata-se de colocar a formação, ou a não aceitabilidade hegemônica de uma formação, não em termos de competências para ensinar como empreendedorismo, mas no entre aprender E desaprender, cultivando as formas de problematizar, sempre provisórias, os modos pelos quais efetivamente se aceita a hegemonia de uma formação linear como pura técnica de ensino. Não se trata de dizer que toda formação é ruim, mas de colocar ou de seguir linhas mutáveis moventes numa atitude teórico prática concernente à não necessidade de tecnizar uma formação e, para distinguir essa posição teórico prático acerca da não necessidade da formação de professores como princípio de inteligibilidade de um ensino, de uma aprendizagem, é preciso pensar formação num território de forças moventes, estudá-la no percurso de uma micropolítica ${ }^{4}$. Porque esse caminho escapa da técnica de aplicação e se constitui, permanentemente, num gesto semi-esboçado, como invenção de si e do mundo. $E$, neste sentido, só é possível pensálo pelos movimentos que os potencializam ou os fragilizam no contexto de uma experiência, de uma formação inventiva. Ou seja, como um campo de relação de forças.

No entanto, uma formação não se estabelece por si só, mas no cotidiano, quando as

4 Esta questão é amplamente analisada em Dias, 2008. 
práticas materializam-se, ganham forma e movimento, de acordo com o uso que se faz delas. As produções da formação inventiva que escapam às formas deterministas e coercitivas são uma prática de resistência e produção de subjetividade. São (trans)formações (DIAS, 2008, DIAS; KASTRUP, 2009), às vezes pouco visíveis, e, não necessariamente em suas manifestações, tomam corpo na potência dos processos de singularização, afirmando políticas diferentes das hegemônicas.

De que maneira uma formação inventiva opera? Deslocando da hierarquia da solução de problemas para a invenção de problemas. Para uma formação inventiva, que funciona como um ensino entre: Que desafios se colocam entre professores, entre alunos, entre conhecer, entre políticas? Como intervir para formar inventivamente num território em que a representação, o conhecer como processamento simbólico é hegemônico? Como evidenciar uma formação inventiva que ajuda a pensar o deslocamento solução de problemas e invenção de problemas?

Para experienciar uma formação inventiva é preciso pensar nas formações como se elas, diariamente, emergissem das experiências. Escapar das pedagogizações antecipadoras das lógicas do consenso, que colocam o conhecer numa busca do equilíbrio, da adaptação, e também deslizar de um tempo linear que dita a verdade esperada de um educador. Algo parecido com o que Benjamin (1996) trata acerca da experiência, do brinquedo e de uma obra monumental. Nas palavras do autor:

Toda experiência profunda deseja, insaciavelmente, até o fim de todas as coisas, repetição e retorno, restauração de uma situação original, que foi seu ponto de partida. 'Tudo seria perfeito, se pudéssemos fazer duas vezes as coisas': a criança age segundo essas palavras de Goethe. Somente, ela não quer fazer a mesma coisa apenas duas vezes, mas sempre de novo, cem e mil. Não se trata apenas de assenhorear-se de experiências terríveis e primordiais pelo amortecimento gradual, pela invocação maliciosa, pela paródia; trata-se também de saborear repetidamente, do modo mais intenso, as mesmas vitórias e triunfos. O adulto alivia seu coração do medo e goza duplamente sua felicidade quando narra sua experiência. A criança recria essa experiência, começa sempre tudo de novo, desde o início. Talvez seja esta a raiz mais profunda do duplo sentido da palavra alemã Spielen (brincar e representar): repetir o mesmo seria seu elemento comum. A essência da representa- ção, como da brincadeira, não é 'fazer como se', mas 'fazer sempre de novo', é a transformação em hábito de uma experiência devastadora. (BENJAMIN, 1996, p. 253)

Tal experiência devastadora é expressão de uma formação inventiva e usufrui o que Varela (1994) chama de representação em sentido fraco. Um método que anima um jogo e se compõe de políticas diárias por meio de um ritmo ensaiado de narrativas, versos, canções e gestos semi-esboçados diários. Das repetições será possível encarnar um conhecer por práticas políticas, emergindo num primeiro momento como hábitos de pensar e de fazer um ensino entre $E$ uma aprendizagem $E$ uma desaprendizagem. É nesse contexto que uma formação inventiva não é melhor ou pior, mas diferente. É uma formação que polemiza representação simbólica e a natureza do saber do mestre, mas ousa e se aventura num conhecer incorporado.

Uma formação inventiva desloca-se para continuamente diferir da padronização e investir na invenção de si e do mundo (KASTRUP, 1999). Ao mesmo tempo em que proliferam práticas políticas, ela produz subjetividades, pois conjuga produção de conhecimento com produção de existência. Ao provocar rupturas uma formação inventiva trabalha sob o signo do novo e do imprevisto. Sua atividade científica integra uma forma de problematização permanente e de rivalidade, promovendo uma estética da existência que liga produção de subjetividade, políticas de cognição, experiência e práticas de um modo que não é nem o dos saberes ditos tradicionais, nem aquele vinculado à uma prontidão para ação construtiva. Suas estratégias abrem-se à desnaturalização e à articulação do improviso com a invenção.

\section{Uma Experiência Para Deslocar Conceitos}

O debate entre os diferentes modos de conhecer e formação de professores fala de um processo político sobre questões da formação, que oferece poucas respostas corretas e passos a seguir, mas põe em movimento muitas inquietações que dão sentido à formação. Os deslocamentos entre os diferentes modos de conhecer e suas políticas mostram que é possível não confundir uma forma de ensinar com um único modo de praticá-lo. 
Um atributo da experiência de uma formação inventiva é a figura do fazer sempre de novo (BENJAMIN, 2000). Neste contexto, como o mestre e o aluno podem criar para si e inventar a si próprios em um meio com tantos modelos precisos, já dados? Para tanto, há necessidade do cultivo dos paradoxos entre aprendizagem E desaprendizagem do prescrito. De que modo? Como alimentar na formação encontros que dão ênfase ao cultivo?

Uma formação inventiva co-funciona num ensaio (DELEUZE, 1997), entendido como experiência modificadora de si e do mundo. Trata-se de uma formação em movimento, de seu corpo vivo, de uma relação entre quem a pratica e a própria formação. Há um campo de relação de forças, com formas e forças. A forma é o ensaio, um cultivo do exercício que possibilite estranhar-se as prescrições. Tais prescrições instalam-se comodamente na formação, sendo necessário resistir. Mas no ensaio é permitido desaprender.

Esse modo de pensar deslocando o si mesmo abre um espaço-tempo da experiência pelo cultivo de uma atitude atenta ao estranhamento de si e do mundo. Essa experiência de estranhamento, segundo Kastrup (2005a), refere-se a uma cognição ampliada e ao conceito de breakdown de Varela (1994, 1995), que o vê como uma experiência capaz de perturbar, de quebrar com a continuidade linear cognitiva, uma problematização que precede à ação (KASTRUP, 1999).

Quando a noção de cognição se limita à inteligência e à solução de problemas ela é trabalhada de forma isolada e, com isso, perde a possibilidade de ser analisada como uma cognição ampliada. Esta pode operar de maneira tensionada, estranhada, perturbada por algo que a force a inventar. Deste modo, uma cognição é ampliada e inventiva quando há ressonância com o conceito de breakdown ou perturbação. Pois este é um argumento fundamental na discussão de que não existe mundo prévio, nem sujeito preexistente. $O$ si e o mundo são forjados pela ação, de modo recíproco e indissociável. O si e o mundo perturbam, mas não informam. Há um processo de transformação permanente. Este conceito responde pelo momento da invenção de problemas produzindo um abalo na noção de solução de problemas.

Uma cognição é ampliada e inventiva quando ela assume um modo circular que se diferencia do movimento linear do cognitivismo. A cognição inventiva e ampliada é experienciada pelas ações de reiterar, retornar, renovar, reinventar, reiterar, recomeçar" (KASTRUP, 2005a, p. 1279). A lógica da cognição inventiva envolve a noção de um aprender circular, e tal ideia indica uma trajetória de inacabamento. Com isso, o deslocamento acontece pela abertura, pela descontinuidade, pelo estranhamento, pela reativação do aprendizado.

A autora faz da invenção um problema, quando recusa a invariância das condições de possibilidades da cognição e reconhece seu caráter temporal e de diferenciação. "A invenção é uma potência que a cognição tem de diferir de si mesma" (KASTRUP, 2005a, p. 1279). Ela é um processo que se liga a diferenciação e a repetição, este último pensado como um fazer sempre de novo.

Este modo de pensar a cognição abre-se a um espaço-tempo da experiência pelo cultivo de uma atitude atenta e encarnada no estranhamento de si e do mundo. Este que, segundo Kastrup (2005a), é referido no conceito de breakdown de Varela $(1994,1995)$, que o vê como uma experiência capaz de perturbar, de quebrar com a continuidade linear cognitiva, uma problematização que precede à ação. Por exemplo, em um semestre letivo tive uma experiência singular ao ministrar uma aula, como professora de filosofia da educação no curso de pedagogia de uma faculdade da Baixada Fluminense do Rio de Janeiro. Era uma turma composta por uma quantidade de alunos muito grande (em torno de 90 alunos), e o espaço físico da sala de aula parecia um pequeno auditório, composto inclusive de um tablado com minha mesa localizada no canto direito. Pela grande concentração de pessoas, as conversas eram inevitáveis, e em determinadas aulas o barulho era ensurdecedor e incomodava com freqüência. No dia da referida aula, sobre as relações saber-poder no campo da educação, percebi que esquecera em casa um livro que necessitaria. Com base em meu repertório, qual a minha reação? Ocorreu uma hesitação em relação ao que fazer e, segundo Varela, a quebra da continuidade, paradoxalmente, assegura o fluir da conduta. O autor afirma que os breakdowns "[ . . . ] são a fonte do lado autônomo e criativo da cognição viva" (VARELA, 1995, p. 21).

Para tornar mais denso o conceito de breakdown e introduzi-lo no tema da formação inventiva, volto ao exemplo do esquecimento 
do livro, que desestruturou a estabilidade da experiência de aula, representada por recognições (que Varela prefere chamar de prestreza para a ação, e que Kastrup denomina de estados de prontidão cognitiva). Ao afetar a prontidão para a aula, o esquecimento provocou uma bifurcação ou quebra na linearidade, abrindo espaço-tempo para uma cognição que funcionou como invenção de problemas. Como agir de modo que a ação fosse adequada? Nesse sentido, o esquecimento, ao perturbar a prontidão, surgiu como invenção quando forjei com os alunos exemplos cotidianos em que fosse possível o comparecimento, na aula propriamente dita, do livro.

O contexto da aula - que tratava as relações saber-poder na educação - foi atravessado pelas conversas paralelas dos alunos, transformando-se num ambiente ensurdecedor. Frente a isso, minha atitude foi continuar a aula sem aumentar o tom da voz, seguindo a sugestão recognitiva, até que uma aluna gritou do fundo da sala: É aula particular! I mediatamente, disse que não e prossegui com a discussão, mas com o continuar das falas paralelas disse àqueles alunos que estavam participando da discussão: Vocês querem ver essa relação se dar aqui? E fui para cima do tablado, ficando em silêncio e de pé em cima da cadeira. Quando subi na cadeira, a turma que falava ativamente produziu um silêncio instantâneo e curioso para o que estava por vir. Minha atitude cognitiva escapou do ponto de vista da lógica, dos mecanismos de representação agrupados nas abordagens ditas abstratas da cognição. Com o gesto concreto foi possível encarnar minha atitude cognitiva no momento efetivo e presente do que experienciei com os alunos. Ou seja, após o silêncio atento e curioso, a aula mudou de plano, engendrando uma circularidade nas falas; meu gesto de subir na cadeira, acompanhado do silêncio, produziu uma discussão acerca das relações saber-poder que geralmente estão presentes em sala de aula. Mas, nesse dia, essas relações encarnaram uma fonte de emergência de correlações sensório-motoras inscritas na experiência presente.

A mudança de atitude cognitiva provocou nos alunos a discussão de questões colocadas por Foucault (2002) em Vigiar e Punir - esse o livro que esquecera de trazer. Tal atitude evocou a discussão do conceito de panópti- $\mathrm{co}^{5}$ no movimento da aula. Com o esquecimento do livro, me privando de ler passagens do texto, a saída encontrada foi, então, criar gestos concretos em que a discussão do referido conceito acontecesse de uma maneira diferente daquela que havia planejado para a aula. Para Kastrup (1999, p. 115), “[ . . . ] o meio comparece perturbando, e não transmitindo informação. Perturbar significa afetar, colocar problema". É importante relembrar, como dito anteriormente, que o exemplo descrito não oferece um modelo a ser seguido e aplicado.

Cognição, nesta perspectiva, não é um domínio de representações, mas um domínio emergente e experiencial do si e do mundo. As relações entre o si e o mundo se constituem permeável às múltiplas perturbações, cujos efeitos não são antecipáveis. A ação vincula-se em larga medida as contingências de improvisação e se dá na experiência, ocorrendo, no entanto, uma redefinição permanente do que importa fazer.

O que aconteceu no referido exemplo foi uma circularidade descontínua, redefinindo o planejamento de aula a partir do domínio da experiência, onde se dá uma emergência das relações com o texto (lido, mas esquecido), com os alunos, com a aula e com uma atitude cognitiva aberta para além da representação e do saber. Vale dizer também que, para Kastrup, o conceito de breakdown de Varela inclui "[ . . . ] no campo da cognição o caráter da imprevisibilidade que toda invenção comporta" (KASTRUP , 1999, p. 132).

A cognição como invenção de si e do mundo desloca uma abordagem abstrata e representacional para a emergência de uma abordagem concreta e experienciada da cognição. Segundo Varela (1994) conhecer = fazer $=$ ser, e está aberto à imprevisilibidades. Tal ideia é avessa às estruturas e leis que tomam a aprendizagem como adaptação ou aquisição e desenvolvimento de habilidades previsíveis e controladas por leis e princípios invariantes. Há um movimento do modelo abstrato e re-

5 Segundo Foucault (2002), o dispositivo panóptico organiza unidades especiais que permitem ver sem parar e reconhecer imediatamente. A lógica é introduzir um estado consciente e permanente de visibilidade que assegura o funcionamento automático do poder. 
presentacional, forçando uma ampliação do sistema cognitivo, "[ . . . ] transformando-o num sistema complexo em que a representação, incluída ao preço de seu enfraquecimento e mesmo de sua subversão, coexiste com os breakdowns" (KASTRUP, 1999, p. 145). Nesse sentido, a autora chama a atenção para a importância de uma cognição pensada pela sua dinâmica e valoriza a abertura para os deslocamentos produzidos:

[ . . . ] é importante notar que, se a dimensão representacional da cognição encontra lugar no interior do sistema autopoiético ${ }^{6}$, o inverso não acontece: não há possibilidade de extrair a invenção, a criação cognitiva, de uma cognição que opera com base num programa fechado, no interior de limites invariantes e intransponíveis. Não há como pensar a heterogênese a partir de um campo limitado de possíveis. Abordagem mais abrangente ou a perspectiva da inclusão faz-se por um descentramento ou por um redirecionamento da investigação científica, o que depende de uma nova maneira de colocar o problema. (KASTRUP, 1999, p. 146)

Uma abordagem ampla da cognição é explorada pelo seu "[ . . . ] meio denso e inventivo, e não em seu núcleo duro e invariante, forçando, assim, os limites do conceito" (KASTRUP, 1999, p. 146). Desse modo, a cognição passa a funcionar fora do registro abstrato, em ligação direta com as forças do mundo e coordenando mente e corpo. A cognição, então, segundo Kastrup (1999, 2005a, 2005b) e Varela (1994, 1995), está inscrita no corpo. Pela inscrição corporal da cognição, na referida aula, foi possível circular e deslocar a representação conceitual do saber-poder e dar lugar a gestos corporificados de conhecimento. Eu mesma pude fazer circular o conhecer e sua produção no âmbito da discussão, nos problemas levantados, nos exemplos dados pelos alunos e nos efeitos que esta aula produziu em outras aulas no decorrer do semestre letivo. A aula era sempre lembrada pelos alunos, gerando uma ressonância do conhecer; ou, como dito anteriormente, o conhecer assume seu caráter cir- cular e se movimenta reincidindo, retornando, renovando, reinventando, reiterando, recomeçando. Como uma aprendiz forjada como obra aberta, foi possível, no referido exemplo, experienciar uma tensão que potencializou deslocar da solução de problemas para a invenção de problemas. Ao mesmo tempo em que criava um problema com o gesto de subir na cadeira, foi necessário, em cada aula subseqüente, formular conceitos temporários e passíveis de serem reformulados, mobilizando a atenção dos alunos durante o percurso de aprendizagem. Um efeito interessante foi produzido; as conversas não cessaram por completo, mas depois da referida aula elas não eram mais ensurdecedoras.

O que aconteceu foi um cultivo dos paradoxos entre aquilo que já se sabia e o que não se sabia acerca do aprender E uma desaprendizagem das atitudes prescritas. Tal cultivo introduziu o aprender na invenção de conceitos, nas problematizações e, principalmente, nos incômodos gerados. O cultivo do paradoxo expressa uma formação que não pode ser aplicada e interpretada, mas experienciada politicamente, numa produção coletiva, forjando sentidos e produzindo efeitos diversos num campo de relação de forças.

Com o exemplo, e sempre correndo risco, tento cercar mais de perto as implicações de uma política de cognição na formação de professores preocupada com produção de subjetividade e com um conhecer enativo. Com este traçado, parece-me importante pensar e fazer uma formação atenta as políticas de cognição que emergem dela e escapem da noção de manutenção do conhecimento desde sempre aí. Sobretudo, foi possível investir na singularidade que permite tanto a professores como a alunos deslizarem de uma noção de representação fazer como se para uma fazer sempre de novo (BENJAMIN, 1996), que investe numa (forma)ação inventiva de professores. Assim, o que há é a expressão de uma política que gera experiências, pequenas invenções, e não uma prescrição metodológica replicável. 


\section{Referências}

BARROS, M. Histórias da Unha do Dedão do Pé do Fim do Mundo. Direção: Evandro Salles. Produção: Bianca Ramoneda e Maria Roth. Rio de Janeiro: Lúmen Argo Arte e Projeto, 1993. 1 DVD.

BENJ AMI N, W. Obras Escolhidas: magia e técnica, arte e política. 7. ed. São Paulo: Brasiliense, 1996.

BENJ AMIN, W. Obras Escolhidas II: rua de mão única. 5. ed. São Paulo: Brasiliense, 2000.

DELEUZE, G. Diferença e Repetição. Rio de Janeiro: Graal, 1988.

DELEUZE, G. L'abécédaire Gilles Deleuze. Paris: Éd. Montparnasse, 1997. 1 Videocassete. Sublinhado em português pelo MEC, TV Escola.

DELEUZE, G.; PARNET, C. Diálogos. Lisboa: Relógio D’Água, 2004.

DIAS, R.O. Deslocamentos na Formação de Professores: aprendizagens de adultos, experiência e políticas cognitivas. 2008. Tese (Doutorado em Psicologia) - Instituto de Psicologia, Universidade Federal do Rio de Janeiro, Rio de Janeiro, 2008, Rio de Janeiro, BR-RJ .

DIAS, R.O.; KASTRUP, V. Sociedade da Capacitação e Políticas de Cognição na Formação de Professores. [S.I.: S.n.], 2009. No prelo.

FOUCAULT, M. Vigiar e Punir: nascimento da prisão. 25. ed. Petrópolis: Vozes, 2002.

FOUCAULT, M. Do Governo dos Vivos. VERVE: revista semestral do Núcleo de Sociabilidade e Libertária, Programa de Estudos Pós-Graduados em Ciências Sociais - NU-SOL, São Paulo, n. 12, p. 270-298, 2007.

KASTRUP, V. A Invenção de Si e do Mundo: uma introdução do tempo e do coletivo no estudo da cognição. Campinas: Papirus, 1999.

KASTRUP, V. Políticas Cognitivas na Formação do Professor e o Problema do Devir-Mestre. Educação e Sociedade, Campinas, v. 26, n. 93, p. 1273-1288, set./dez. 2005a.

KASTRUP, V. O Devir-Consciente em Rodas de Poesia. Revista do Departamento de Psicologia da UFF, Niterói, v. 17 , n. 2, p. $45-60$, jul./dez. 2005b.

KASTRUP, V.; TEDESCO, S.; PASSOS, E. Políticas da Cognição. Porto Alegre: Sulina, 2008.

MATURANA, H.; VARELA, F. A Árvore do Conhecimento: as bases biológicas da compreensão humana. 2. ed. São Paulo: Palas Athena, 2002.

VARELA, F. Conhecer: as ciências cognitivas, tendências e perspectivas. Lisboa: Instituto Piaget, 1994.

VARELA, F. Sobre a Competência Ética. Lisboa: Ed. 70, 1995.

VARELA, F. O Reencantamento do Concreto. In: PELBART, P.P.; COSTA, R. (Org.). Cadernos de Subjetividade: o reencantamento do concreto. São Paulo: Hucitec, 2003. P. 71-86.

VARELA, F.; THOMPSON, E.; ROSCH, E. A Mente Incorporada: ciências cognitivas e experiência humana. Porto Alegre: Artmed, 2003.

Recebido em agosto de 2009

Aprovado para publicação em setembro de 2009

\section{Rosimeri de Oliveira Dias}

Professora Adjunta da Faculdade de Formação de Professores da Universidade do Estado do Rio de Janeiro - email: rosimeri. dias@uol.com.br 